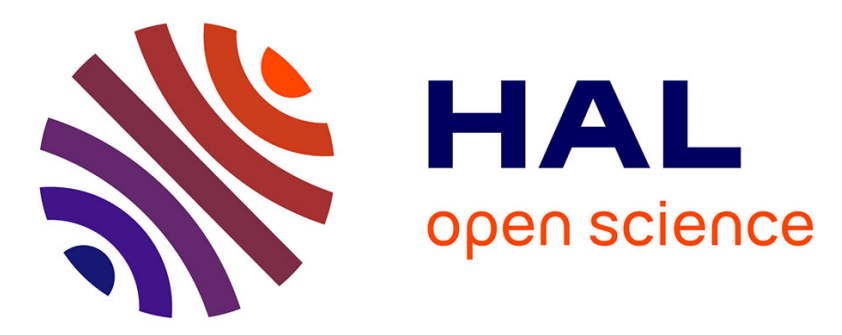

\title{
Determination of two-electron crystal field parameters in some neodymium compounds
}

\author{
M. Faucher, O. Moune, David Garcia
}

\section{To cite this version:}

M. Faucher, O. Moune, David Garcia. Determination of two-electron crystal field parameters in some neodymium compounds. Journal de Physique II, 1993, 3 (7), pp.961-969. 10.1051/jp2:1993176 . jpa-00247891

\section{HAL Id: jpa-00247891 https://hal.science/jpa-00247891}

Submitted on 1 Jan 1993

HAL is a multi-disciplinary open access archive for the deposit and dissemination of scientific research documents, whether they are published or not. The documents may come from teaching and research institutions in France or abroad, or from public or private research centers.
L'archive ouverte pluridisciplinaire HAL, est destinée au dépôt et à la diffusion de documents scientifiques de niveau recherche, publiés ou non, émanant des établissements d'enseignement et de recherche français ou étrangers, des laboratoires publics ou privés. 


\title{
Determination of two-electron crystal field parameters in some neodymium compounds
}

\author{
M. Faucher $\left({ }^{1}\right)$, O. K. Moune $\left({ }^{1}\right)$ and D. Garcia $\left({ }^{2}\right)$ \\ (') ERS 70 du CNRS, PCM, Ecole Centrale, Grande Voie des Vignes, 92295 Chatenay-Malabry \\ Cedex, France \\ (2) SII, 83 Bd Vincent Auriol, 75013 Paris, France
}

(Received 14 January 1993, revised 15 March 1993, accepted 9 April 1993)

\begin{abstract}
Two-electron, fourth rank $(k=4)$, crystal field parameters are fitted for four neodymium compounds: $\mathrm{LiYF}_{4}: \mathrm{Nd}^{3+}, \mathrm{Nd}_{2} \mathrm{O}_{2} \mathrm{~S}, \mathrm{Y}_{2} \mathrm{O}_{3}: \mathrm{Nd}^{3+}$ and $\mathrm{Nd}_{2} \mathrm{O}_{3}$, displaying a strong experimental/calculated discrepancy for the ${ }^{2} \mathrm{H}_{11 / 2}$ level. The final mean deviation for all the levels is $2 \mathrm{~cm}^{-1}(20 \%)$ lower than that attained with the standard (one-particle) theory. The compound

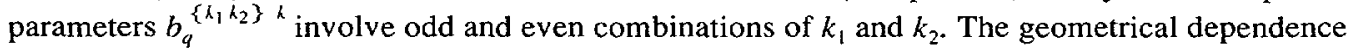
$(q)$ seems to indicate a drift towards a $\mathrm{C}_{\infty}$ site symmetry caused by axial ligands. The diagonal matrix elements of the correlated crystal field are smaller than the off-diagonal matrix elements except for twin terms.
\end{abstract}

\section{Introduction.}

The pronounced discrepancy of the experimental/calculated fit of the ${ }^{2} \mathbf{H}_{11 / 2}$ energy levels of $\mathrm{Nd}^{3}+$ was stressed ever since the first precise crystal field analyses of $\mathrm{Nd}^{3+}$ spectra. The calculated splitting of the level is often tiny with respect to the experimental one $[1,2]$. Previously [3], we gave a summary of experimental results and pointed out that the magnitude of the discrepancy seemed to be related to the coupling with a «twin $»$ level displaying the same $S, L$ and $J$ values. The calculated quasi-degeneracy [4] occurs owing to a cancellation in products of free ion quantities. For any two coupled terms, the splitting of one of the lower levels is given to the second perturbation order by :

$$
S=c /\left(e_{1}+e_{2}\right)^{2}\left[u_{2}\left(e_{1}^{2}+e_{12}^{2}\right)+u_{1}\left(e_{2}^{2}+e_{12}^{2}\right)-2 e_{12} u_{12}\left(e_{1}+e_{2}\right)\right]
$$

where $c$ is a geometrical factor while the quantities $e$ and $u$ are given by :

$$
\begin{array}{ll}
e_{\imath}=\left\langle{ }^{2 S+1} L(i)\left\|H_{\mathrm{el}}\right\|^{2 S+1} L(i)\right\rangle & e_{i \jmath}=\left\langle{ }^{2 S+1} L(i)\left\|H_{\mathrm{el}}\right\|^{2 S+1} L(j)\right\rangle \\
u_{\imath}=\left\langle{ }^{2 S+1} L(i)\left\|U^{4}\right\|^{2 S+1} L(i)\right\rangle & u_{\imath \jmath}=\left\langle{ }^{2 S+1} L(i)\left\|U^{4}\right\|^{2 S+1} L(j)\right\rangle
\end{array}
$$

$e_{1}, e_{2}$ and $e_{12}$ are linear combinations of the Racah parameters for $\mathrm{Nd}^{3+}$ and their values depend slightly on the compound. For $\mathrm{Nd}_{2} \mathrm{O}_{3}, e_{1}, e_{2}$ and $e_{12}$ are equal to 16017,3939 and 
$5810 \mathrm{~cm}^{-1}$ respectively. $u_{1}, u_{2}$ and $u_{12}$ are constants, given by Nielson and Koster's tables. For $\mathrm{Nd}^{3}+$, they are equal to $-0.3028,0.495$, and 0.62113 respectively.

In (1), the expression between brackets cancels for the levels of the lower term ${ }^{2} \mathrm{H}(2)$; a fact which is inconsistent with experimental results. A constant change in free ion quantities leads to correct calculated splittings. Utilizing the experimental splittings, calling $c_{2}$ and $c_{12}$ the multipliers of the $\left\langle\left\|U^{4}\right\|\right\rangle$, and replacing all the other quantities in the bracket by their values, we find that a convenient splitting is obtained for $c_{2}$ and $c_{12}$ such that:

$$
c_{2}-c_{12}=-0.75
$$

The value $c_{2}=0.25$ was proposed in reference [5]. Then $c_{12}$ remains equal to 1 as shown by (3), and the calculated upper ${ }^{2} \mathrm{H}(1)$ levels are unchanged. This correction is efficient for all the neodymium compounds. It strongly improves the calculated ${ }^{2} \mathrm{H}(2)$ levels but also, to a lower extent, the fit of the whole experimental spectrum. Another choice among an infinity is the multiplication of $c_{12}$ by $\sqrt{3}$ with $c_{2}$ unchanged. This second choice also insures a correct fit of the lower ${ }^{2} \mathrm{H}(2)$ levels whereas the calculated upper ${ }^{2} \mathrm{H}(1)$ levels spread out. Unfortunately, the experimental energies of the latter are often unknown. The proposed corrections, though always efficient and easy to apply (they are made in the framework of the ordinary one-electron crystal field analysis), have no theoretical justification.

A forward step was then made by $\mathrm{Li}$ and Reid [6] who demonstrated that fourth rank correlated crystal field operators are responsible for the missing interaction.

The asymmetric correlation crystal field in lanthanides and actinides has been theoretically examined in a relatively small number of papers, due to Judd [7, 8], Newman and co-workers $[11,14]$, Kibler and Grenet [15], and Reid [16, 17]. Amid these papers, there are quite a few which deal with practical determinations for a double reason : firstly because of the too large number of two-electron parameters and secondly the lack of precision of experimental data. In reference [6], $\mathrm{Li}$ and Reid show precisely that the addition to the standard Hamiltonian of twoelectron orthogonal crystal field operators of rank four (namely $g_{10 \mathrm{~A}}^{(4)}$ ) improves the experimental/calculated fit. The authors chose spectra containing over 100 crystal-field levels and results are given for 6 rare earth compounds, namely $\mathrm{NdODA} \mathrm{NdAlO}_{3}$, and neodymium doped $\mathrm{LaCl}_{3}, \mathrm{LiYF}_{4}, \mathrm{YAG}, \mathrm{LaF}_{3}$. Large data sets are available for $\mathrm{YAG}$ and $\mathrm{LaF}_{3}$ and a good agreement requires the introduction of $g_{2}^{\prime(4)}$ and $g_{10 \mathrm{~B}}^{(4)}$ in order to fit the ${ }^{2} \mathrm{~F}(2)$ high-lying levels around $40,000 \mathrm{~cm}^{-1}$.

In the present work, we follow a slightly different track : instead of looking for a correlated operator having small effects on all the levels except ${ }^{2} \mathrm{H}(2)_{1 / 12}$, we fit directly the parameters acting on two individual electrons. For this purpose, we utilize the computer program ATOME [18] which calculates matrix elements and performs the matrix diagonalization of the $4 f^{n}$ configurations on a basis of Slater determinants. The parameters for coupled states are subsequently calculated utilizing the tables of fractional parentage for the $f^{3}$ configuration.

\section{Correlated crystal field operators and matrix elements.}

The empirical correction proposed in our earlier work [5] involved a fourth rank one-particle crystal field operator touching the orbital part of the $4 \mathrm{f}$ electron wavefunction only. The associated parameter was always equal to a constant fraction of the ordinary crystal field.

Reference [6] introduced a fundamental new feature i.e. correlated parameters.

Presently, we shall keep these three characteristics (rank four, correlated operators acting on the orbital part of the $4 f$ wave-functions) but without imposing the magnitude of the correlated interaction. Besides we do not restrict ourselves to one particular operator. 
The correlation energy between pairs of electrons [9] is given by :

$$
U=\sum_{k_{1}, k_{2}} \sum_{q_{1}, q_{2}} b_{q_{1} q_{2}}^{k_{1} k_{2}} \cdot u_{q_{1}}^{k_{1}}(1) \cdot u_{q_{2}}^{k_{2}}(2)
$$

The two-electron parameters $b_{q_{1} q_{2}}^{k_{1} k_{2}}$ can be expressed in terms of compound parameters $b_{q}^{\left\{k_{1}, k_{2}\right\} k}$ by inverting relation (3.8) in reference [9]:

$$
b_{q_{1} q_{2}}^{k_{1} k_{2}}=\sum_{k \cdot q}(-1)^{k_{1}-k_{2}+q}(2 k+1)^{1 / 2}\left(\begin{array}{lll}
k_{1} & k_{2} & k \\
q_{1} & q_{2} & -q
\end{array}\right) \cdot b_{q}^{\left\{k_{1}, k_{2}\right\}}
$$

The expression for the correlated energy becomes then :

$$
U=\sum_{k_{1}, k_{2}} \sum_{q_{1}, q_{2}} \sum_{k_{,} q}(-1)^{k_{1}-k_{2}+q}(2 k+1)^{1 / 2}\left(\begin{array}{ccc}
k_{1} & k_{2} & k \\
q_{1} & q_{2} & -q
\end{array}\right) \cdot b_{q}^{\left\{k_{1} k_{2}\right\} k} u_{q_{1}}^{k_{1}}(1) \cdot u_{q_{2}}^{k_{2}}(2) .
$$

The rank $k$ of the tensor is here equal to 4 and $q$ ranges from -4 to $4 . k_{1}$ and $k_{2}$, the ranks of the components are limited by the triangular conditions of the $3 j$ symbol. The computer program ATOME used for the data fits requires matrix elements calculated between product states which are just written as:

$$
\begin{aligned}
& \left\langle\ell_{1} m_{1}, \ell_{2} m_{2}|U| \ell_{3} m_{3}, \ell_{4} m_{4}\right\rangle= \\
& \sum_{\ell_{1}, \ell_{2}} \sum_{q_{1}, q_{2}} \sum_{k_{1} q}(-1)^{k_{1}-k_{2}-\ell_{1}-\ell_{2}+m_{1}+m_{2}+q}\left(\begin{array}{ccc}
k_{1} & k_{2} & k \\
q_{1} & q_{2} & -q
\end{array}\right) \cdot(2 k+1)^{1 / 2} \\
& \quad\left(\begin{array}{ccc}
\ell_{1} & k_{1} & \ell_{3} \\
-m_{1} & q_{1} & m_{3}
\end{array}\right) \cdot\left(\begin{array}{ccc}
\ell_{2} & k_{2} & \ell_{4} \\
-m_{2} & q_{2} & m_{4}
\end{array}\right) b_{q}^{\left\{k_{1}, k_{2}\right\} k}
\end{aligned}
$$

$\ell_{1}, \ell_{2}, \ell_{3}$, and $\ell_{4}$ referring to $\mathrm{f}$ orbitals are equal to 3 , the values of interest for $k_{1}$ and $k_{2}$ range therefore between 1 and 6 , and $k$ between 1 and 12 . The study is limited here to $k=4$; The 11 crystal field parameters $b_{q}^{\left\{k_{1}, k_{2}\right\}+4}$ respecting the triangular conditions of the $3 j$ symbol occur for $k_{1}$ and $k_{2}$ equal to 1,$3 ; 1,5 ; 2,2 ; 2,4 ; 2,6 ; 3,3 ; 3,5 ; 4,4 ; 4,6 ; 5,5$ and 6,6 respectively. It was not possible to perform a fit by taking even values of $k_{1}$ and $k_{2}$ only.

\section{Datasets and fits.}

The fits were performed on four datasets i.e. $\mathrm{LiYF}_{4}: \mathrm{Nd}^{3+}[19], \mathrm{Nd}_{2} \mathrm{O}_{2} \mathrm{~S}[20], \mathrm{Y}_{2} \mathrm{O}_{3} . \mathrm{Nd}^{3+}$ $[21,22]$ and $\mathrm{Nd}_{2} \mathrm{O}_{3}[1]$. The range of the measured energies is not very extended. It spreads out to about $34,000,30,000,20,000$ and $30,000 \mathrm{~cm}^{-1}$ only for the four compounds respectively, which were chosen mainly because of their large ${ }^{2} \mathbf{H}(2)_{11 / 2}$ discrepancy. Compounds $\mathrm{LaCl}_{3} \cdot \mathrm{Nd}^{3+}$ and $\mathrm{NdAlO}_{3}$ despite their large dataset were not utilized because the ${ }^{2} \mathbf{H}(2)_{1 / 2}$ discrepancy is not pronounced (their fourth order parameters are small).

To obtain starting values of the parameters, we write the linear system linking together the level splittings and the values of the $b_{q}^{\left\{k_{1}, k_{2}\right\} k}$ (written for shortness $\left\{k_{1} k_{2}\right\}$; the $q$ dependence will be discussed later on). Using the fact that the one-electron standard crystal field analysis gives a good fit for all except the ${ }^{2} \mathrm{H}(2)_{1 / 2}$ levels, we assume that the second member of the system is null except for the discrepant levels. The resolution of the system yields a set of starting values which are then allowed to vary freely. 
The three parameters $\{35\},\{44\}$, and $\{66\}$ decrease quickly to zero and are withdrawn from the set. The remaining set of eight parameters could apparently not be reduced further.

The final fitted values of the $b_{0}^{\left\{k_{1}, h_{2}\right\}}$ are listed in table I and the corresponding mean deviations are reported in table II : $d_{1}, d_{2}, d_{3}$, and $d_{4}$ (uncorr) are obtained from an uncorrelated calculation excluding the discrepant ${ }^{2} \mathrm{H}(2)_{11 / 2}$ levels and therefore optimizing the fit of the other levels. $d_{1}\left(d_{2}\right)$ are the absolute (relative) deviations of the ${ }^{2} \mathbf{H}(2)_{1 / 2}$ levels: $d_{3}\left(d_{4}\right)$ are the absolute (relative) deviations of the other levels. Similarly, $d_{1}, d_{2}$, $d_{3}$, and $d_{4}$ (corr) are obtained from a correlated calculated calculation including the discrepant ${ }^{2} \mathrm{H}(2)_{1 / 2}$ levels and therefore optimizing the fit of all the levels. $d_{1}\left(d_{2}\right)$ are the absolute (relative) deviations of the ${ }^{2} \mathrm{H}(2)_{1 / 2}$ levels ; $d_{3}\left(d_{4}\right)$ are the absolute (relative) deviations of the other levels.

The probable error was evaluated from the change of parameters after an extra refinement cycle once the lowest mean deviation is obtained. It amounts approximately to $\pm 15 \mathrm{~cm}^{-1}$ for $\{1,3\},\{1,5\},\{2,2\}$ and $\{2,4\} ; \pm 25 \mathrm{~cm}^{-1}$ for $\{2,6\},\{3,3\},\{4,6\}$ and $\{5,5\}$.

For the compounds studied, the discrepancy of the ${ }^{2} \mathrm{H}(2)_{1 / 2}$ levels without correlation (uncorr : $d_{1}, d_{2}$ ) is near $50 \mathrm{~cm}^{-1}$ The fits of the other levels are not bad: the absolute and relative deviations are close to 15 and $11 \mathrm{~cm}^{-1}$ respectively (uncorr : $d_{3}, d_{4}$ ). The introduction of correlated parameters not only allows the fit of the ${ }^{2} \mathbf{H}(2)_{1 / 2}$ levels (corr : $d_{1}$, $d_{2}$ ) but causes a $2 \mathrm{~cm}^{-1}$ decrease of the mean deviation of the other levels (corr: $\left.d_{3}, d_{4}\right)$. There is but one exception which will be discussed later on.

Concerning the $q$ dependence of the $b_{q}\left\{k_{1}, k_{n}\right\} k$ the former work on the subject $[5,6]$ suggests it might be just the same as for the one-particle standard crystal field. Some new features appear in the present study: for $\mathrm{LiYF}_{4}: \mathrm{Nd}^{3+}$ and $\mathrm{Y}_{2} \mathrm{O}_{3}: \mathrm{Nd}^{3+}$, the best agreement between experimental and calculated values is obtained with the above assumption. For $\mathrm{LiYF}_{4} \cdot \mathrm{Nd}^{3+}$, and using the one-particle ratio $b_{4}^{4} / b_{0}^{4}=1.21$, the refinement leads to an absolute deviation equal to $13.3 \mathrm{~cm}^{-1}$ and a relative deviation within sublevels equal to $9.5 \mathrm{~cm}^{-1}$ for 121 levels.

Table I. - Fitted two electron crystal field parameters $b_{0}^{\left\{k_{1} k_{2}\right\} 4}$ with different $q$ dependencies.

\begin{tabular}{|l|r|r|r|r|r|r|r|r|}
\hline \multicolumn{1}{|c|}{$k_{1}, k_{2}=$} & \multicolumn{1}{c|}{1.3} & 1.5 & \multicolumn{1}{c|}{2.2} & 2.4 & \multicolumn{1}{c|}{2.6} & \multicolumn{1}{c|}{3.3} & \multicolumn{1}{c|}{4.6} & \multicolumn{1}{c|}{5.5} \\
\hline $\mathrm{LiYF}_{4}: \mathrm{Nd}^{3+}(\mathrm{a})$ & -61 & 190 & 256 & -279 & -1131 & -1049 & 857 & -623 \\
\hline $\mathrm{Nd}_{2} \mathrm{O}_{2} \mathrm{~S}\left({ }^{\mathrm{a}}\right)$ & 89 & 165 & -312 & -220 & 921 & 1221 & -958 & 1371 \\
$\mathrm{Nd}_{2} \mathrm{O}_{2} \mathrm{~S}\left({ }^{\mathrm{c}}\right)$ & 54 & 770 & -831 & -301 & 2319 & 2422 & -902 & 2318 \\
\hline $\mathrm{Y}_{2} \mathrm{O}_{3}: \mathrm{Nd}^{3+}\left({ }^{\mathrm{a}}\right)$ & 18 & -75 & 868 & 193 & -945 & -2231 & 1167 & -2058 \\
\hline $\mathrm{Nd}_{2} \mathrm{O}_{3}\left(^{\mathrm{a}}\right)$ & -58 & 123 & 58 & 265 & 400 & 89 & 476 & -54 \\
$\mathrm{Nd}_{2} \mathrm{O}_{3}(\mathrm{~b})$ & -202 & 321 & 124 & 673 & 969 & 39 & 1143 & -322 \\
$\mathrm{Nd}_{2} \mathrm{O}_{3}(\mathrm{c})$ & -1147 & 1075 & -575 & 2470 & 2313 & -938 & 3582 & -2841 \\
\hline
\end{tabular}

(a) With the same $q$ dependency as the one-electron parameters: $b_{4}^{4} / b_{0}^{4}=1.21$ for $\mathrm{LiYF}_{4}: \mathrm{Nd}^{3+}$; $b_{3}^{4} / b_{0}^{4}=-1.47$ and -2.76 for $\mathrm{Nd}_{2} \mathrm{O}_{2} \mathrm{~S}$ and $\mathrm{Nd}_{2} \mathrm{O}_{3}$ respectively $; b_{2}^{4} / b_{0}^{4}=1.1$ and $b_{4}^{4} / b_{0}^{4}=-0.89$ for $\mathrm{Y}, \mathrm{O}_{3}: \mathrm{Nd}^{3+}$.

(b) With $b_{3}^{4} / b_{0}^{4}=-1$.

(c) With only $q=0$ correlated parameters. 
Table II. - Number of energy levels $(N)$ and mean experimental/calculated deviations $\left(d_{n}\right)$ in $\mathrm{cm}^{-1}$ in the uncorrelated (uncorr) and correlated (corr) calculation. $d_{1}$ : absolute deviation of the ${ }^{2} \mathrm{H}(2)_{11 / 2}$ sublevels. $d_{2}$ : relative deviation of the ${ }^{2} \mathrm{H}(2)_{11 / 2}$ sublevels with respect to their barycenter. $d_{3}$ : absolute deviation of the other sublevels. $d_{4}$ : relative deviation of the other sublevels with respect to their barycenter.

\begin{tabular}{|l|l|r|r|r|r|}
\hline Compound & & $d_{1}$ & \multicolumn{1}{c|}{$d_{2}$} & $d_{3}$ & $d_{4}$ \\
\hline $\mathrm{LiYF}_{4}: \mathrm{Nd}^{3+}$ & uncorr & 43.1 & 43.1 & 15.5 & 11.8 \\
$(N=121)$ & corr $\left(\mathrm{C}_{4 \mathrm{v}}\right)\left(^{\mathrm{a}}\right)$ & 5.6 & 5.6 & 13.3 & 9.5 \\
\hline $\mathrm{Nd}_{2} \mathrm{O}_{2} \mathrm{~S}$ & uncorr & 67.2 & 59.2 & 16.2 & 10.9 \\
$(N=89)$ & corr $\left(\mathrm{C}_{3 \mathrm{v}}\right)\left(^{\mathrm{a}}\right)$ & 17.7 & 3.8 & 13.9 & 8.2 \\
& corr $\left(\mathrm{C}_{\infty \mathrm{v}}\right)\left(^{\mathrm{c}}\right)$ & 19.5 & 6.7 & 13.7 & 8.6 \\
\hline $\mathrm{Y}_{2} \mathrm{O}_{3}: \mathrm{Nd}^{3+}$ & uncorr & 68.1 & 68.1 & 15.9 & 10.2 \\
$(N=85)$ & corr $\left(\mathrm{C}_{2 \mathrm{v}}\right)\left(^{\mathrm{a}}\right)$ & 10.3 & 10.3 & 14.3 & 8.9 \\
\hline $\mathrm{Nd}_{2} \mathrm{O}_{3}$ & uncorr & 56.5 & 56.5 & 14.6 & 11.2 \\
$(N=86)$ & corr $\left(\mathrm{C}_{3 \mathrm{v}}\right)\left(^{\mathrm{a}}\right)$ & 20.9 & 20.9 & 14.6 & 12.0 \\
& corr $\left(\mathrm{C}_{3 \mathrm{v}}\right)\left(^{\mathrm{b}}\right)$ & 17.7 & 17.7 & 14.2 & 11.9 \\
& corr $\left(\mathrm{C}_{\infty \mathrm{v}}\right)\left(^{\mathrm{c}}\right)$ & 11.5 & 10.7 & 12.7 & 10.5 \\
\hline
\end{tabular}

(a) With the same $q$ dependence as the one-electron parameters: $b_{4}^{4} / b_{0}^{4}=1.21$ for $\mathrm{LiYF}_{4}: \mathrm{Nd}^{3+}$; $b_{3}^{4} / b_{0}^{4}=-1.47$ and -2.76 for $\mathrm{Nd}_{2} \mathrm{O}_{2} \mathrm{~S}$ and $\mathrm{Nd}_{2} \mathrm{O}_{3}$ respectively $; b_{2}^{4} / b_{0}^{4}=1.1$ and $b_{4}^{4} / b_{0}^{4}=-0.89$ for $\mathrm{Y}_{2} \mathrm{O}_{3}: \mathrm{Nd}^{3+}$.

(b) With $b_{3}^{4} / b_{0}^{4}=-1$.

(c) With only $q=0$ correlated parameters.

However, the available experimental ${ }^{2} \mathrm{H}(2)_{11 / 2}$ spectrum only displays five lines casting some uncertainty on the adequacy of the assignment. For $\mathrm{Y}_{2} \mathrm{O}_{3} \cdot \mathrm{Nd}^{3+}$, the six lines of the ${ }^{2} \mathbf{H}(2)_{11 / 2}$ sublevel have been observed [23] and the one-electron ratio also seems correct (see Tab. II, the $d_{2}$ value). The point symmetry $\left(C_{2}\right)$ allows complex $b_{q}^{\left\{k_{1}, k_{2}\right\} k}$, yet it makes no detectable difference whether we chose real or complex correlated parameters. We adopt real values with ratios equal to the one-particle modulus ratio

$$
\left(\left|b_{2}^{4}\right| / b_{0}^{4}=1.1 ;\left|b_{4}^{4}\right| / b_{0}^{4}=-0.89\right) .
$$

For $\mathrm{Nd}_{2} \mathrm{O}_{3}$, when the fit is made with a «normal » $q$ dependence $\left(\left|b_{3}^{4}\right| / b_{0}^{4}=-2.76\right)$, the final relative deviation of the levels other than ${ }^{2} \mathrm{H}(2)_{11 / 2}$ is worse with than without correlation (Tab. II : $12.0 / 11.2 \mathrm{~cm}^{-1}$ ). Instead, if we adopt axial parameters with only a $q=0$ component, the relative deviation drops down to $10.5 \mathrm{~cm}^{-1}$ while the parameters drastically increase by one order of magnitude. Another attempt was made with an intermediate value for the ratio i.e. $b_{3}^{4} / b_{0}^{4}=-1$. The final mean deviation and parameters then display intermediate values as shown in tables I and II.

For $\mathrm{Nd}_{2} \mathrm{O}_{2} \mathrm{~S}$, the mean deviation is approximately the same whether the «normal » dependence $\left(b_{3}^{4} / b_{0}^{4}=-1.47\right)$ or $b_{3}^{4}=0$ is chosen. In the latter case, and as stated for $\mathrm{Nd}_{2} \mathrm{O}_{3}$, the fitted parameters strongly increase. 
The different $q$ dependences which are stated in the compounds studied are perhaps related to the presence of an axial ligand in both the sesquioxide and the sesquisulfide, whereas the cubic oxide and the oxyfluoride have a coordination polyhedron which is wide open along the symmetry axis.

The parameters strongly increase when only $q=0$ parameters are kept. We were expecting a multiplication by four for $\mathrm{Nd}_{2} \mathrm{O}_{3}$ and by a little more than two for $\mathrm{Nd}_{2} \mathrm{O}_{2} \mathrm{~S}$ (according to the one-electron $b_{3}^{4} / b_{0}^{4}$ ratio). This evolution is respected for $\mathrm{Nd}_{2} \mathrm{O}_{2} \mathrm{~S}$ but not for $\mathrm{Nd}_{2} \mathrm{O}_{3}$ where the final axial parameters are more than ten times stronger than the initial ones. We shall verify later on that they produce in fact a nearly constant effect on the ${ }^{2} \mathrm{H}(2)_{11 / 2}$ sublevels.

\section{Matrix elements between coupled states.}

In addition to the elementary correlated parameters listed in table $\mathrm{I}$, it is desirable to calculate the resulting reduced matrix elements on the basis of the coupled states of the $f^{3}$ configuration. This is done in two steps, by using tensor operator techniques [24] ; firstly the matrix elements are calculated for the states of the parent configuration $f^{2}$, by means of the following expression :

$$
\begin{aligned}
& \left\langle S(\ell \ell) L\left\|U^{\left(k_{1} k_{2}\right) k}\right\| S^{\prime}(\ell \ell) L^{\prime}\right\rangle= \\
& =\sum_{k_{1} k_{2}} \delta\left(S, S^{\prime}\right) \cdot b_{0}^{\left\{k_{1}, h_{7}\right\} k}\left[(2 L+1) \cdot\left(2 L^{\prime}+1\right) \cdot(2 k+1)\right]^{2}\left\{\begin{array}{ccc}
\ell & \ell & k_{1} \\
\ell & \ell & k_{2} \\
L & L^{\prime} & k
\end{array}\right\} .
\end{aligned}
$$

Next the matrix elements for the $\mathrm{f}^{3}$ states are evaluated utilizing the coefficients of fractional parentage [25]:

$$
\begin{aligned}
\left\langle S(\bar{L} \ell) L\left\|U^{\left(k_{1} h_{2}\right) k}\right\| S^{\prime}\left(\bar{L}^{\prime} \ell\right) L^{\prime}\right\rangle & = \\
& =3 \sum_{\bar{L} \bar{L}^{\prime}} \delta\left(S, S^{\prime}\right),\left(L\{\mid \bar{L}) .\left(L^{\prime}\left\{\mid \bar{L}^{\prime}\right)\left\langle\bar{S} \bar{L}\left\|U^{\left(k_{1} k_{2}\right) k}\right\| \bar{S}^{\prime} \bar{L}^{\prime}\right\rangle .\right.\right.
\end{aligned}
$$

The matrix elements of the total fourth rank correlated crystal field between the coupled states of the $f^{3}$ configuration were calculated by using the set of correlated parameters listed in table I. The contributions were not separated so that the values obtained reflect the total fourth order correlated field.

We state the following: the matrix elements calculated for the four samples are not just proportional one to one which rules out the attractive hypothesis that only one unique combination of elementary correlated parameters is necessary. This is in agreement with the statement made by $\mathrm{Li}$ and Reid in reference [6] that several orthogonal correlated parameters are needed to fit the $\mathrm{YAG}: \mathrm{Nd}^{3}+$ levels.

The diagonal matrix elements of correlated crystal field parameters for untwinned levels are small at least for the low-lying levels and this probably explains why they are not much felt in the energy range usually explored.

The values of the off-diagonal matrix elements for untwinned levels are rather scattered but a common feature is that they are generally two to three times larger than the diagonal ones. Their influence is damped by the energy gap between levels.

In table III the values of the diagonal and off-diagonal matrix elements calculated for the ${ }^{2} \mathrm{H}$ and ${ }^{2} \mathrm{~F}$ submatrices are reported. For these twinned levels, the case is different from above : the calculated off-diagonal matrix elements are not systematically small. Here, we should stress a point discussed in part III i.e. that table I lists the value of axial parameters only, which 
Table III. - Matrix elements calculated within the ${ }^{2} \mathrm{H}$ and ${ }^{2} \mathrm{~F}$ blocs. Reduced matrix elements of $g_{0 \mathrm{~A}}^{(4)}$ from reference [6] are given for comparison, (a) (b) as in table $I I$.

\begin{tabular}{|l|c|r|r|r|r|r|}
\hline Compound & $\left\langle{ }^{2} \mathrm{H} 1\|\|^{2} \mathrm{H} 1\right\rangle$ & $\left\langle{ }^{2} \mathrm{H} 2\|\|^{2} \mathrm{H} 2\right\rangle$ & $\left\langle{ }^{2} \mathrm{H} 1\|\|^{2} \mathrm{H} 2\right\rangle$ & $\left\langle{ }^{2} \mathrm{~F} 1\|\|^{2} \mathrm{~F} 1\right\rangle$ & $\left\langle{ }^{2} \mathrm{~F} 2\|\|^{2} \mathrm{~F} 2\right\rangle$ & $\left\langle{ }^{2} \mathrm{~F} 1\|\|^{2} \mathrm{~F} 2\right\rangle$ \\
\hline $\mathrm{LiYF}_{4}: \mathrm{Nd}^{3+}$ & 30 & 255 & -219 & -49 & 110 & -11 \\
$\mathrm{Nd}_{2} \mathrm{O}_{2} \mathrm{~S}\left(\mathrm{C}_{3 \mathrm{v}}\right)$ & 120 & -239 & 228 & 186 & 100 & 75 \\
$\mathrm{Nd}_{2} \mathrm{O}_{2} \mathrm{~S}\left(\mathrm{C}_{\alpha \mathrm{v}}\right)$ & 413 & -761 & 450 & 127 & 242 & 114 \\
$\mathrm{Y}_{2} \mathrm{O}_{3}: \mathrm{Nd}^{3+}$ & 21 & 227 & -432 & -319 & -75 & -207 \\
$\mathrm{Nd}_{2} \mathrm{O}_{3}\left(\mathrm{C}_{3 v}\right)\left({ }^{\mathrm{a}}\right)$ & 8 & -208 & -1 & -155 & -46 & -60 \\
$\mathrm{Nd}_{2} \mathrm{O}_{3}\left(\mathrm{C}_{3 \mathrm{v}}\right)\left({ }^{\mathrm{b}}\right)$ & 61 & -483 & -26 & -386 & -135 & -154 \\
$\mathrm{Nd}_{2} \mathrm{O}_{3}\left(\mathrm{C}_{\alpha \mathrm{v}}\right)$ & 416 & -1163 & -82 & -1158 & -717 & -361 \\
$g_{10}^{(4)}$ & 0.009 & 0.518 & & & 0.256 & \\
\hline
\end{tabular}

explains why the matrix elements for the same compound in different point site hypothèses display different magnitudes. The reduced matrix elements for the orthogonal correlated operator $g_{10 \mathrm{~A}}^{(4)}$ from reference [6] are also listed. The matrix elements of ${ }^{2} \mathrm{H}$ for $\mathrm{LiYF}_{4} \cdot \mathrm{Nd}^{3+}$ seem to be mainly due to $g_{10 \mathrm{~A}}^{(4)}$ which is in agreement with Li and Reid's statement. As for the other compounds, it is obvious from the table that the total crystal field cannot be constructed with the aid of $g_{10}^{(4)}$ only.

The first and second columns in table IV list the values of $S$ and $S^{\prime}$ (given by expression 1 in part I) proportional to the ${ }^{2} \mathrm{H}(2)$ splitting due to the fitted correlated crystal field and the oneelectron crystal field respectively. These are axial terms which contain neither the geometrical ( $q$ dependence) nor the $3 j$ symbols depending on $q$ and the moments $m$ (expression (7)). Therefore, to permit a homogeneous comparison of the results, the axial parameters are scaled so that they contain all the strength of the field components. Column 3 gives the ratio $S^{\prime} / S$ which ranges from 6 to 11 and shows what is really missing in the standard theory to make the experimental and calculated splittings fit together.

\section{Conclusions.}

The exposed work consisted in fitting directly two electron crystal field parameters of rank four in four neodymium compounds. Eight elementary parameters were kept involving odd and even $k_{1}$ and $k_{2}$ components for the compound parameter. In the present case, this rules out the intervening of $\mathbf{C}_{q}^{k}$ operators.

The parameters converged towards stable and reasonably constant values, even starting from vastly different sets. The level stabilizing the fit is the discrepant ${ }^{2} \mathrm{H}(2)_{11 / 2}$ which is a rare indicator of crystal field avatars since the effect on its splitting of the ordinary one-electron crystal field is close to zero.

Satisfactory fits were obtained for $\mathrm{LiYF}_{4} \cdot \mathrm{Nd}^{3+}, \mathrm{Nd}_{2} \mathrm{O}_{2} \mathrm{~S}, \mathrm{Y}_{2} \mathrm{O}_{3} \cdot \mathrm{Nd}^{3+}$ and $\mathrm{Nd}_{2} \mathrm{O}_{3}$. The corresponding parameter sets display together no evident relationship. The calculations of $\mathrm{Ng}$ and Newman [12] lead to a theoretical prediction of all the many-body contributions to the total rank four correlated crystal (except the $4 \mathrm{f} \rightarrow n \mathrm{f}$ contributions which were unprecisely determined). It is satisfactory that in the present work, we stated a spontaneous vanishing of the $b_{q}{ }^{\left\{k_{1}, k_{2}\right\}}{ }^{4}$ parameters for $k_{1}, k_{2}=\{3,5\}$ and $\{4,4\}$ as in their predictions (Tab. XI in Ref. [12], second paper). Besides, the rather large values obtained for $\{2,6\},\{4,6\}$ and $\{3,3\}$ also agree with the theory (though not the signs). The $\{3,3\}$ parameter is ascribed by the authors of reference [12] to excitations from the lanthanide core to excited states. 
Table IV. - Resulting crystal field magnitudes $\left(S^{\prime}\right.$ and $S$ ) acting on the ${ }^{2} \mathbf{H}(2)$ levels. $S^{\prime}$ and $S$ correspond to the correlated and one-electron components respectively. - for $S^{\prime}$ : the reduced matrix elements calculated in this work and listed in table III - for $S$ : the reduced matrix elements of $U^{4}$ multiplied by :

$B_{0}^{h} \cdot(-1)^{1} \cdot(2 \ell+1) \cdot\left(\begin{array}{lll}\ell & \ell & 4 \\ 0 & 0 & 0\end{array}\right)$ (the $\ell$ dependent factors account for the fact that the oneelectron crystal field operator is a $C_{q}^{h}$ tensor operator). $S^{\prime}$ and $S$ have been scaled so as to contain the strength of all the components of the crystal field by the expression :

$$
S^{\prime}(S) \rightarrow S^{\prime}(S) \cdot\left(\left(\sum b_{q}^{k}\right)^{2}\right)^{1 / 2} / b_{0}^{k}
$$

The ratio $S^{\prime} / S$ is given in the third column. $\left(^{\mathrm{a}}\right),\left(^{\mathrm{b}}\right)$ as in table $I I$.

\begin{tabular}{|c|c|c|c|}
\hline Magn. $\left(\mathrm{cm}^{-1}\right)$ & $S^{\prime}$ & $S$ & $S^{\prime} / S$ \\
\hline LiYF $_{4}: \mathrm{Nd}^{3+}$ & 634 & 87 & 7.3 \\
\hline $\mathrm{Nd}_{2} \mathrm{O}_{2} \mathrm{~S}\left(\mathrm{C}_{3 \mathrm{v}}\right)$ & -676 & -66 & 10.2 \\
$\mathrm{Nd}_{2} \mathrm{O}_{2} \mathrm{~S}\left(\mathrm{C}_{\infty \mathrm{v}}\right)$ & -766 & -66 & 11.6 \\
\hline $\mathrm{Y}_{2} \mathrm{O}_{3}: \mathrm{Nd}^{3+}$ & 940 & 140 & 6.7 \\
\hline $\mathrm{Nd}_{2} \mathrm{O}_{3}\left(\mathrm{C}_{3 \mathrm{v}}\right)\left({ }^{\mathrm{a}}\right)$ & -601 & -104 & 5.8 \\
$\mathrm{Nd}_{2} \mathrm{O}_{3}\left(\mathrm{C}_{3 \mathrm{v}}\right)\left(^{\mathrm{b}}\right)$ & -571 & -104 & 5.5 \\
$\mathrm{Nd}_{2} \mathrm{O}_{3}\left(\mathrm{C}_{\infty \mathrm{v}}\right)$ & -749 & -104 & 7.2 \\
\hline
\end{tabular}

Given the fact that the ${ }^{2} \mathrm{H}(2)_{11 / 2}$ discrepancy can always be accounted for in the framework of the ordinary one-electron parametrization with a simple constant modification of the $U^{4}$ tables touching just this term, it is surprising to find such a complex substructure in the twoelectron parameter set. We have found rather small diagonal and larger off-diagonal matrix elements except for coupled (twin) terms.

We have also stated a new fact, i.e. the seemingly large influence of axial ligands. For instance the correlation field of $\mathrm{Nd}_{2} \mathrm{O}_{3}$ is best fitted by assuming the $\mathrm{Nd}^{3+}$ ion is in a purely axial site symmetry. $\mathrm{Nd}_{2} \mathrm{O}_{2} \mathrm{~S}$ is nearly fitted as well in an axial symmetry as in the true $\mathrm{C}_{3 \text { v }}$ symmetry.

A persistant feature concerns the magnitude of the correlated crystal field which is always six to ten times stronger than the ordinary one-electron interaction within the discrepant level. This does not preclude the existence of correlated crystal field parameters of rank 2 and 6 , some of which can be deduced from the presently fitted sets.

We have yet to test the adequacy of the fit for the upper levels of the configuration which have not been measured and are essential to verify the validity of the parameter set. Our hope is the possibility of generalization and application to other configurations such as the $\mathrm{f}^{2}\left(\operatorname{Pr}^{3+}\right)$ and $\mathrm{f}^{6}\left(\mathrm{Eu}^{3+}\right)$ configurations. 


\section{References}

[1] Caro P., Derouet J., Beaury L. and Soulié E., J. Chem. Phys. 70 (1979) 2542.

[2] Soulllat J. C., Rossat-Mignod J. and Linares C., Phys. status solidi (b) 52 (1972) 601.

[3] Faucher M., Garcia D., Caro P., Derouet J. and Porcher P., J. Phys. France 50 (1989) 219.

[4] Faucher M. and Garcia D., C.R. Acad. Sci. Paris II-307 (1988) 2015.

[5] Faucher M., Garcia D. and Porcher P., C.R. Acad. Sci. Paris 308 (1989) 603.

[6] Li C. L. and ReID M. F., Phys. Rev. B 42 (1990) 1903.

[7] Judd B. R., Phys. Rev. Lett. 39 (1977) 242.

[8] Judd B. R., J. Chem. Phys. 66 (1977) 3163.

[9] Bishton S. S. and Newman D. J., J. Phys. C. . Solid St. Phys. 3 (1970) 1753.

[10] Siu G. G. and Newman D. J., J. Phys. C. . Solid St. Phys. 16 (1983) 7019.

[11] Crosswhite H. and Newman D. J., J. Chem. Phys. 81 (1984) 4959.

[12] Ng B. and Newman D. J., J. Chem. Phys. 87 (1987) 7096 and 7110.

[13] Yeung Y. Y. and Newman D. J., J. Chem. Phys. 86 (1987) 6717.

[14] Newman D. J. and NG B., J. Phys. C. . Solid St. Phys. 21 (1988) 3273.

[15] Kibler M. and Grenet G., Int. J. Quantum Chem. 29 (1986) 485.

[16] Reid M. F., J. Chem. Phys. 87 (1987) 2875.

[17] ReID M. F. and Li C. L., Eur. J. Sol. State, Inorg. Chem. 28 (1991) 171.

[18] Garcia D. and Faucher M., J. Chem. Phys. 90 (1989) 5280.

[19] Da Gama A. A. S., De Sa G. F., Porcher P. and Caro P., J. Chem. Phys. 75 (1981) 2583.

[20] Tchertanov M., Moune O. K., Piriou B., Dexpert-Ghys J., Faucher M. and GuitTard M., submitted to $J$. Luminescence.

[21] Chang N. C., J. Chem. Phys. 44 (1966) 4044.

[22] Chang N. C., Gruber J. B., Leavitt R. P. and Morrison C. A., J. Chem. Phys. 76 (1982) 3877.

[23] Pedrini C., Jacquier B. and Boulon G., personal communication.

[24] Judd B. R., Operator Techniques in Atomic Spectroscopy, (McGraw-Hill, 1963).

[25] JudD B. R., « Notes of Lectures at La Sorbonne, Paris » (1962), unpublished. 